\title{
The passive in adolescents with Down syndrome: a case study
}

\author{
Maraci Coelho de Barros Pereira Rubin
}

The Universidade Federal do Paraná, Curitiba, Brazil

\begin{abstract}
This paper shows that some individuals with Down syndrome are capable of producing, imitating (repeating) and comprehending passive sentences, even though group studies indicate that this is not the norm. Experimental tests of elicited production, repetition and comprehension of passive and active sentences applied in ten adolescents with Down syndrome, speakers of Portuguese, showed that out of the ten adolescents, one, $\mathrm{Fa}$, is able to produce, imitate and comprehend passive sentences. It is hypothesised that, when there is no comprehension, or when the comprehension of reversible passives is unstable, the passive is understood as active, because the first noun of the passive sentence is interpreted as agent/causer of the action/non-action. This hypothesis is strong inasmuch as it assumes that both active and passive have very similar initial derivations. There is not, however, strong evidence that the nine adolescents interpret the passive as active. But if it is assumed that their chance results in comprehension of the passive is due to the fact that they are beginning to understand it, then it could be said that, for around $50 \%$ of the time, the adolescents with Down syndrome interpret the passive as active. Fa, on the other hand, does not interpret the passive as active, as she produces, imitates and comprehends the passive structure very well.
\end{abstract}

Keywords: passive, active, sentence, noun, (thematic) role, derivation, initial structure/derivation, (above)/(below) chance levels

\section{Introduction}

Studies of the syntax of the population with Down syndrome revealed that this population does not produce (Fowler et al., 1994; Rubin, 2004) or comprehend passives $^{1}$ (Rondal et al., 1988; Ring \& Clahsen, 2003) and does not imitate (repeat) long passives ${ }^{2}$ (Rubin, 2004). This paper shows that, contrary to the majority of the population with Down syndrome, some individuals with Down syndrome are capable of producing, imitating and comprehending the passive structure.

Investigating the passive structure in a group of adolescents with Down syndrome by means of experimental tests (Rubin, 2004), one subject, Fa, seemed to be different from the others. She was very talkative, her speech was very clear (except for the phoneme $/ \mathrm{k} /$, which was absent) and her ideas were conveyed in an easy, organised and fluent manner. And, more importantly, her performance in the experiments showed that she produces, imitates and comprehends long and short passives, ${ }^{3}$ whereas the other subjects do not. This paper presents her results in production, imitation and comprehension of the passive, elicited with experimental tests, and compares them with the results obtained by the other subjects, as a group.

It has been shown (Bever, 1970; Maratsos, 1974; Strohner \& Nelson, 1974) that typically developing small children

\footnotetext{
${ }^{1}$ An example of a passive sentence is The cat was chased by the dog. ${ }^{2}$ Long passives present two (or more) nouns, like the sentence of footnote 1.

${ }^{3}$ Short passives present only one noun: The girl was praised.
} 
interpret reversible passives ${ }^{4}$ as active sentences. ${ }^{5}$ Bever's study demonstrated that pre-school children adopt the Actor-action-object strategy to interpret the sequence Noun-Verb-Noun, no matter if a sentence is passive or active. The above strategy then allows reversible passives to be interpreted as actives, with the first noun as the agent/causer. ${ }^{6}$ In other words, a small child presented with a passive sentence like The cat was chased by the dog will interpret it as The cat chased the dog, since it is possible for either of the two nouns to be the agent of the action. It may be that the difficulties the population with Down syndrome has with the passive lies in the identification of the passive sentence with an active sentence, specifically, that this population interprets the first noun of a passive sentence as agent/causer of the action/nonaction. ${ }^{7}$ This paper shows that $\mathrm{Fa}$, an adolescent with Down syndrome, is an exception.

\section{The passive}

In comparing a passive sentence with an active sentence, the first thing one notices is that they express the same thing. In both The cat was chased by the dog and The dog chased the cat the idea is that a canine chased a feline. But how does the listener know these two sentences mean the same? Because of the role each noun has in the sentences. In every sentence, the nouns have (thematic) roles, and they are essential for sentence interpretation (comprehension). So, for example, an agent or a causer is an animated being or something that acts upon someone or something, be it a concrete action (like chase) or a non-action (like love), and the patient or the theme is someone or something that suffers an action or a nonaction. In the sentences above, the agent and the patient of the action to chase remain the same, but they appear in different positions: in the active, the agent of the action comes first, and the patient comes after the verb; in the passive, the patient comes first, and the agent comes after the verb.

The passive structure has raised much interest ever since the dawn of generative linguistics (Chomsky, 1957), but this is not the place to go into the details of its grammar. For the purposes of this work, it suffices to say that different authors have different ideas of how it is structured. For many of them, the passive has a different structure from the active, and for some of them (Jaeggli, (1986), Baker et al., (1989), Boeckx, (1998)), active and passive are fundamentally similar. So Boeckx, (1998), for example, argues that the initial structure ${ }^{8}$ of both constructions is just about the same. Figure 1 shows an approximation of what

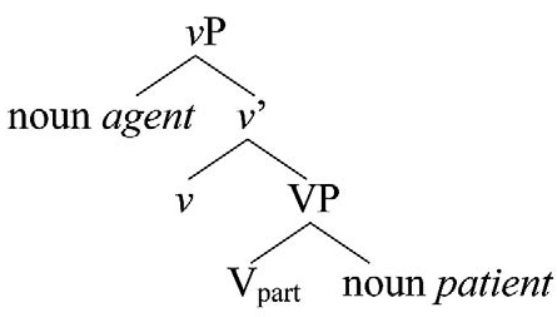

\section{Figure 1.}

would be the initial structure of both passive and active sentences (do not mind the $v s$ and $v P s$ - concentrate on the position of the nouns agent and patient).

The positions of the noun agent and the noun patient in the graphic (which is called the syntactic tree) have to be these, because it is there that the nouns get their agent and patient roles. And that is for good. Once a noun receives its role, it will accompany it wherever it goes. And nouns have to go somewhere else, in order to obtain a passive structure. So to end up with an active sentence, the positions of the nouns do not change in relation to one another in the tree. That is, the noun agent is pronounced first, and the noun patient after that. To end up with a passive sentence, the position of both nouns has to change. So to come up with a passive sentence (produce or understand), the person has at some moment after the stage presented in (1) to put the noun patient where the noun agent is. It is probable that a person who does not understand the passive does the following: when she/he hears a passive sentence, the person will immediately put (merge) the noun she/he hears first where the noun agent is. In a passive sentence, that noun happens to be the patient. Once the person does that, there is no more remedy: that noun will gain the agent role, and the sentence is irreversibly an active sentence.

The passive is a structure of late acquisition, and is only mastered, i.e., used appropriately in the expected contexts and situations, at around 9 years of age (Horgan, 1978). Children of around 4 years of age start to understand the passive, but are not able to produce it (De Villiers \& de Villiers, 1978, cited in Sudhalter \& Braine, 1985). Younger children do not understand it (Harwood, 1959 cited in Sudhalter \& Braine, 1985). As has already been said, the population with Down syndrome does not produce or understand the passive, and does not imitate long passives. The hypothesis for this behaviour is that they give an active interpretation for it. With this hypothesis in sight, the acquisition data of the passive and active is considered. The results will show that Fa correctly interprets the passive structure.

\footnotetext{
${ }^{4} \mathrm{~A}$ reversible passive is a passive where either of the two nouns can be the agent of the sentence. So, we can either have The cat was chased by the dog or The dog was chased by the cat. Note that we can have The girl ate the fruit, but not The fruit ate the girl. ${ }^{5}$ An example of an active sentence is The dog chased the cat. ${ }^{6}$ See section 2 for a definition of agent/causer. ${ }^{7}$ See section 2 for enlightenment on action and non-action verbs. ${ }^{8}$ The structures of the sentences are slowly constructed or derived. So the initial derivation of a structure is the first steps in its construction.
} 


\section{The experiments}

\section{Participants}

Fa is $19 ; 11$ years old, with a mental age of $6 ; 6$ years. She has finished junior high school, but was attending the last year again, at a middle class school in Curitiba, Brazil, attended by typically and atypically developing children and adolescents. She is monolingual of Portuguese and has trisomy 21. The other nine participants were two young women and seven young men, attending the same school. They are between $12 ; 0$ and $21 ; 3$ years of chronological age (mean 16;6), mental age between $5 ; 1$ and 6;6 (mean 5;8), all monolingual of Portuguese. They were from middle class backgrounds, most of them were in elementary school, and two are at a level equivalent to pre-school. According to parental information, eight participants have trisomy 21, and one is mosaic. All ten participated in all the experiments.

\section{Production: the synonym experiment ${ }^{9}$}

The objective of this experiment was to tap into the production of the passive structure of adolescents with Down syndrome.

\section{Material and procedure}

In this experiment, twelve active sentences, six with action and six with non-action verbs, were used. The investigator explained that she was going to say a sentence, to which the subject had to pay attention, because he/she would have to make another sentence saying the same thing the investigator had said, except that his/ her sentence had to start with the investigator's two last words. At this point, the investigator would read the first sentence, for example, O menino ama os gatos "The boy loves the cats", and would tell the subject that he/she should start his/her sentence with os gatos "the cats". The investigator prompted the subject saying os gatos, using an intonation that indicated that the sentence should be continued.

\section{Results and discussion}

Table 1 shows the percentage of correct responses in the Synonym experiment. The maximum score possible (the roof) is six passive sentences at each condition: action and non-action verbs.

Fa produced long passive sentences with action verbs $83.3 \%$ of the time, and with non-action, $50 \%$ of the time.

\begin{tabular}{lcc}
\hline \multicolumn{3}{l}{ Table 1: Production in the Synonym experiment } \\
\hline Participants & Action & Non-action \\
\hline $\mathrm{Fa}$ & $83.3 \%$ & $50 \%$ \\
Group & $0 \%$ & $0 \%$ \\
\hline
\end{tabular}

So Fa produced more passives with action verbs. These results clearly reveal Fa's capacity for producing long passive sentences with action and non-action verbs. The other nine participants did not produce any passive sentences.

A production experiment is considered well designed if it is uniquely felicitous, i.e., if it is restricted in such a way that the only possible answer is the target structure. The production experiment applied in this investigation is not uniquely felicitous, as it permits alternative answers to the passive. The table shows that the group did not produce any passive sentences. This result, however, does not guarantee that the adolescents with Down syndrome do not produce the passive, since the experiment is not uniquely felicitous in eliciting the passive. But it was decided to apply it anyway because it is virtually impossible to design a production experiment in Portuguese that leads to a passive sentence as the only possible answer. Here some subjects produced alternative sentences, among them active sentences. So again, the fact that the group did not produce any passives does not mean they cannot actually produce it. But they did not produce any passive, and this result, as we will see, corroborates the results obtained with imitation and comprehension of the passive. And if there is no comprehension or imitation, there certainly is no production.

These results are the same as those obtained by Fowler et al., (1994). In this study, done with four adolescents with Down syndrome between 10;9 and 13;0 of chronological age (mean 12;7), mental age between 6 and 7 years (mean $6 ; 3$ ), the authors examined samples of their spontaneous speech, collected in a naturalistic situation. The talk was centred on a big toy house, with furniture and miniature people. The adolescents were encouraged to talk about the objects, their own house, their own family, and to make up conversations while playing. No passives were found.

\section{Imitation}

The objective of this experiment was to verify whether adolescents with Down syndrome are able to repeat long and short passive sentences, with action and non-action verbs.

\footnotetext{
${ }^{9}$ This experiment should be called almost-synonym, as the passive and active sentences do not have exactly the same meaning. But since the experiment is known by this name, it was decided to maintain it.
} 


\section{Material}

In this experiment, there was only linguistic material: six long and six short passive sentences, with action and non-action verbs. The test for the long passives was applied first. The same sentences used for this test were used for the short passives test, without the by-phrase, ${ }^{10}$ naturally. Each test had two batteries, ${ }^{11}$ one starting with action verbs, and the other with non-action verbs.

\section{Procedure}

The investigator read a passive sentence twice and asked the participant to repeat it. It was emphasised that the subject would have to wait for the sentence to be read twice, and only then should he/she repeat it, as closely as possible to what was heard. But some subjects tried to repeat it while the investigator was reading, and this resulted in three or more readings of some sentences to some subjects. At each repetition, the subjects were praised.

Long sentences were considered as good repetitions if they a) had preposition, b) did not maintain the article (Ø Ronaldo conhecido por todos "Ø Ronaldo is known by everyone", c) employed another verb, but in the participle (O sorvete foi chupado pela criança "the ice cream was sucked by the child". Sentences were not considered as good repetition if they a) had no preposition $(A$ pedra foi jogada Ø o menino "the stone was thrown $\emptyset$ the boy"), b) had no auxiliary verb (Os jogos $\emptyset$ jogados por todo mundo "the games $\emptyset$ played by everyone"), and c) had no grammatical subject (Ø Foi assistido pelos jovens " $\emptyset$ was watched by the young people"). The repetition of short passives that had no auxiliary verb were not considered as good repetitions ( $A$ bola $\emptyset$ chutada "The ball $\emptyset$ kicked"), but sentences that employed another tense for the auxiliary verb were taken into consideration.

\section{Results and discussion}

Table 2 shows the mean of correct imitation of long and short passives, with action and non-action verbs, in simple arithmetic. The roof is 6 in each test.

Table 2 clearly shows the difference between Fa's and the group's responses: Fa's results are at ceiling, ${ }^{12}$ and the group's are below chance ${ }^{13}$ in the long passive, and at chance $^{14}$ in the short passive.

According to Lust et al., (1998), the capacity to imitate seems to be innate, which does not mean that anything

\begin{tabular}{|c|c|c|c|c|}
\hline \multirow{2}{*}{ Participants } & \multicolumn{2}{|c|}{ Long Passive } & \multicolumn{2}{|c|}{ Short Passive } \\
\hline & Action & N/action & Action & N/action \\
\hline $\mathrm{Fa}$ & $100 \%$ & $100 \%$ & $100 \%$ & $100 \%$ \\
\hline Group & $25 \%$ & $11.6 \%$ & $56 \%$ & $56 \%$ \\
\hline
\end{tabular}

can be imitated at any time during the child's development. For the child to imitate a new, complex behaviour, his/her mind needs to have developed the cognitive structure required for the task. So imitation is not a passive copy of the stimulus, but its reconstruction. In language development this is also true: the child can repeat a structure only if it is part of his/her grammatical competence. Thus repetition reflects cognitive competence. So if the child is able to correctly repeat a sentence, we can conclude that the structure is part of her/his competence. If he/she cannot repeat a sentence, it is because he/she cannot generate (produce or understand) it yet.

Since we are dealing with atypical individuals, the impossibility of repeating a structure could be due to nonlinguistic difficulties, such as lack of memory to retain the sentence heard (Marcel et al., 1995). Nevertheless, the results of this experiment corroborate Fa's and the group's results in production. So it seems that, besides the lack of memory to retain the sentence heard, the group of adolescents with Down syndrome lacks competence to produce and to imitate the passive, although they performed at chance in the imitation of short passives. Fa's results on the other hand show her competence to produce and imitate passives.

\section{Comprehension experiments ${ }^{15}$}

Four comprehension experiments were conducted. Three experiments tapped into the comprehension of reversible and irreversible, long and short passive, with action and non-action verbs, and of correspondent active sentences, by individuals with Down syndrome. The first experiment was an act-out task, called Act-out. The other experiment was of picture selection, called Picture selection. The last experiment involves questions about sentences, and is called Asking. The first experiment to be applied was the Act-out, followed by the Picture Selection and Asking, to all participants. Each test came in the

\footnotetext{
${ }^{10}$ The by-phrase is the agent/causer of the action/non-action of a passive sentence. So in the sentence The cat was chased by the dog, by the dog is the by-phrase. ${ }^{11}$ The batteries of a test are versions of the test. The content of the batteries is the same, but there are always one or more differences, for example, the order of the presentation of the sentences. Usually half of the subjects receive one battery, and the other half, the other battery, randomly. ${ }^{12} \mathrm{~A}$ result is at ceiling when the subject got all the responses correct. ${ }^{13} \mathrm{~A}$ result is below chance when the total number of correct responses (between two possible answers for each sentence) is inferior to around $45 \% .{ }^{14}$ At chance results have a range of around $45 \%$ to $60 \%$ of correct responses (between two possible answers). This type of result does not permit one to draw strong conclusions. ${ }^{15}$ For more details of each experiment, see Rubin (2004).
} 
same order for the participants: first came the tests for the long passive, followed by the ones for the short passive, for all the experiments. Only after all the tests for the passive had been applied, came those of the active voice. The fourth experiment tapped into the comprehension of the first noun of reversible passive sentences, and it is called Interrogating the agent of the action. All the tests of the four experiments have a roof of 8 correct responses (except one, whose roof is 6), where two responses are possible.

\section{Comprehension experiment 1: Act-out}

This experiment tapped into the comprehension of long and short passives with action and non-action verbs, and the correspondent active sentences by adolescents with Down syndrome.

\section{Material and Procedure}

In this experiment seven fur animal toys and bath accessories were used. The linguistic material was reversible passives and active sentences involving action verbs. There were two batteries of sentences, and their difference lies in the order of the sentences. The investigator introduces (or elicits) the toys to the participant, and says a sentence for the participant to act out with the toys.

\section{Results}

To test the interaction between the type of subject and the type of passive, the percentage of correct responses was used, in order to standardise the value of the variable correct response between 1 and 0 , independently of the possible number of correct answers (6 or 8 ). Table 3 shows the results.

The group behaved at chance in all conditions of the passive, and above chance in the active. The passive results

\begin{tabular}{|c|c|c|c|}
\hline Subjects & Passive & Mean & Active \\
\hline \multirow[t]{2}{*}{$\mathrm{Fa}$} & Short & $87.5 \%$ & \multirow[b]{2}{*}{$100 \%$} \\
\hline & Long & $50 \%$ & \\
\hline \multirow[t]{2}{*}{ Group } & Short & $46.2 \%$ & \multirow[b]{2}{*}{$81.2 \%$} \\
\hline & Long & $45 \%$ & \\
\hline
\end{tabular}

do not permit the conclusion that the adolescents with Down syndrome do not understand the short passive. But it cannot be said that they understand it either. What could be said is that they probably have an unstable comprehension of the short passive, meaning that they are starting to comprehend it. ${ }^{16}$ These results are not surprising though, as they are corroborated by the imitation test for the short passive.

Fa's results in the short passive and the active are above chance, ${ }^{17}$ whereas in the long passive they are at chance. Her results in the long passive are surprising, for she produced only long passives in the production experiment. If it is true that comprehension precedes production, then some unknown factors must have interfered in her behaviour, such as lack of attention. Or, alternatively, she may have misinterpreted the structure.

\section{Comprehension experiment 2: Picture selection}

This experiment tapped into the comprehension of long and short passive sentences, with action and non-action verbs, and the correspondent active sentences, by way of picture selection.

\section{Material}

A total of thirty-two drawings portrayed sixteen scenes with action, and sixteen with non-action verbs. Two batteries of sentences were made, and their main difference lies in the change of the nouns' roles: one battery had sentences like $O$ filho foi coberto pela mãe "The son was covered by the mother", the other had sentences like $A$ mãe foi coberta pelo filho "The mother was covered by the son" (Hsu \& Hsu, 1998). One battery started with action verbs, the other, with non-action verbs. One battery was given to half of the participants, and the other to the other half, randomly.

The scenes with non-action verbs were represented with thought balloons coming out of the head of one character, containing the other character of the sentence (Maratsos et al., 1985). Each character from whose head the balloon issued had a suitable facial expression.

\section{Procedure}

The investigator said a sentence twice, then showed two drawings to the participant: one represented the sentence said by the investigator (the drawing correctly codified the thematic relations of the sentence $)^{18}$; the other drawing showed inversed thematic relations. While

\footnotetext{
${ }^{16}$ The possibility of making such an assumption is based on partial results of a research in progress (Rubin, in progress), that shows that typical children between 3 and 3,9 years old do interpret the first noun of a passive sentence as agent/causer. That is, if three year olds have below chance results in understanding the passive, it could be assumed that chance results by older individuals mean unstable comprehension, and not lack of comprehension. ${ }^{17}$ Above chance results have a range of around $80 \%$ to $100 \%$ of correct responses (between two possible answers). ${ }^{18}$ Thematic relations of the sentence refer to the role each noun bears in the sentence.
} 
presenting the drawings, the investigator said the sentence two more times, and asked the participant to make his/her choice, by pointing to the drawing that corresponded to the sentence heard (Rondal et al., (1988)). The training for this experiment consisted in talking about six collages, which introduced the convention used to express the action/non-action of the verb (thought balloon).

\section{Results and discussion}

Table 4 shows the results of the experiment Picture selection (the maximum score possible is 8 in each condition).

It is clear from the results that Fa's comprehension of long passives with both kinds of verb is at chance in this experiment. These results corroborate the findings of the Act-out, where she also had chance results with the long passive. But as we said before, these results go against the findings of the production experiment, when Fa produced long passives. As to the short passive, she behaved almost above chance with non-action verbs, and above chance with action verbs, corroborating the results of the Act-out experiment. In regard to the active voice, $\mathrm{Fa}$ behaved at ceiling.

The group had below chance results in the long passive with action verbs. Their results in the other conditions are around chance, and they are corroborated by the imitation and the Act-out experiments. As to the active voice, the group behaved almost above chance in the action condition, and around chance in the non-action, suggesting that they must have had some difficulties with the experiment as a whole.

\section{Comprehension experiment 3: Asking}

This experiment tapped into the comprehension of semantically reversible long passives with action and non-action verbs, and the correspondent active sentences, using questions asked to the subjects about sentences said by the investigator (Maratsos et al., 1985).

\section{Material}

Sixteen sentences were tested: eight reversible passives with action verbs and eight reversible passives with nonaction verbs. Two batteries of sentences were made: one battery tested the action verbs first, and the other tested the non-action verbs first. Half of the subjects received one battery, and the other half received the other battery, randomly.

\section{Procedure}

The investigator said a sentence, and asked the subject two questions about it. The first question interrogated the logical subject (noun agent), and the second interrogated the logical object (noun patient): for the sentence $O$ menino foi arranhado pelo colega "The boy was scratched by the classmate", the first question was quem arranhou o colega? "who scratched the classmate?", and the second was quem foi arranhado? "who was scratched?". Only when the two questions about the sentence were correctly answered did the subject score a point.

\section{Results and discussion}

Table 5 shows the results in the experiment Asking. The roof is 8 correct responses in each condition.

\begin{tabular}{|c|c|c|c|c|}
\hline $\begin{array}{l}\text { Table 5: Mea } \\
\text { of group, ty } \\
\text { experiment }\end{array}$ & $\begin{array}{l}\text { of corr } \\
\text { of sen } \\
\text { king }\end{array}$ & $\begin{array}{l}\text { ct respon } \\
\text { ence and t }\end{array}$ & $\begin{array}{l}\text { as a } \\
\text { e of }\end{array}$ & $\begin{array}{l}\text { ction } \\
\text { b in the }\end{array}$ \\
\hline & Reve & ible Long & & rsible \\
\hline Participants & & ssive & & tive \\
\hline & Action & Non/action & Action & Non/action \\
\hline $\mathrm{Fa}$ & $87.5 \%$ & $100 \%$ & $100 \%$ & $100 \%$ \\
\hline Group & $61 \%$ & $66 \%$ & $79 \%$ & $87.5 \%$ \\
\hline
\end{tabular}

Fa's results are at ceiling in three of the four conditions, and above chance in the action condition. So this experiment is crucial to show that she can understand long passives, after all.

The group's results are only above chance in the active voice. In the two conditions of the passive they are at chance. These results are corroborated by the Imitation and the Act-out experiments. 


\section{Comprehension experiment 4: Interrogating the agent of the action}

The objective of this experiment is to verify whether and how much adolescents with Down syndrome interpret the first noun of a long passive sentence as agent/causer, by way of a question about the agent/causer of the action/ non-action of a passive sentence.

\section{Material}

This experiment is in reality part of the experiment Asking, that pertaining to the first question. Whereas in the Asking there were two questions about the passive sentence, in the Interrogating the agent of the action there was only one, and in the first question the patient is not involved. See the sub-section Material of the experiment Asking for the material of this experiment.

\section{Procedure}

The investigator read a sentence to the subject, asked him/ her a question about the agent/causer of the action/nonaction. For example, for the sentence $A$ menina foi esfregada pela mãe "The girl was scrubbed by the mother", the question was quem esfregou? "who scrubbed?”.

\section{Results and discussion}

Table 6 shows the results for the experiment Interrogating the agent of the action. The roof is 8 , in each condition:

Table 6. Mean of correct responses as a function
of group and type of verb in the experiment
Interrogating the Agent of the Action
\begin{tabular}{lcr}
\multicolumn{3}{c}{ Reversible long passives } \\
\hline Participant & Action & N/action \\
\hline Fa & $62.5 \%$ & $87.5 \%$ \\
Group & $43.7 \%$ & $57.5 \%$
\end{tabular}

The mean percentage of correct responses of the group in the reversible passive with both types of verbs is at chance. This does not provide strong evidence that the group perceives the first noun of the passive as the agent/causer of the action/non-action. Possibly, as already suggested, the results at chance levels could mean that the group is starting to understand it (see sub-section Results and discussion of the Act-out. See also footnote 17). If that is true, then these results are saying that the adolescents with Down syndrome perceive the first noun of the passive as the agent/causer of the action/non-action around $50 \%$ of the time. These results are corroborated by the results of the Act-out and the Asking experiments.

Fa's results are above chance with non-action verbs, but around chance with action verbs. Her results with action verbs come as a big surprise. But these results are contradicted by all the other tests for the short passive with action verbs, where she got only above chance results. Based on the results just mentioned, it could be concluded that Fa does not misinterpret the first noun of short passive sentences.

\section{General discussion of the results}

The results of the production, imitation and the first three comprehension experiments show that none of the group of adolescents with Down syndrome produce passives or imitate long passives, that they struggle to imitate short passives, and they understand long and short passives at chance level. The chance level results are attributed to the fact that the group is starting to understand the passive. Fa's results show that she produces, imitates and comprehends long and short passives with action and nonaction verbs. The conclusion that she understands long passives was reached through the experiment Asking, since her results in the long passive with the Act-out and the Picture selection were at chance. These chance results could be due to Fa's lack of attention. The results obtained by the group could also be attributed to this reason, but it should also be mentioned that they did not show any above chance results in any of the tests for the passive, which suggests that they must have a genuine difficulty with the passive structure.

The experiment Interrogating the agent of the action suggests that the group interprets the first noun of the passive as agent/causer around $50 \%$ of the time. These results corroborate the results obtained with all the experiments, which were at chance or below chance level. Fa's results suggest that she correctly interprets the first noun of passive sentences with non-action verbs. Her results with action verbs were at chance, but her above chance results in all the other tests for the short passive with action verbs lead us to the conclusion that she does not misinterpret the first noun of short passive sentences.

It is possible that the lack of comprehension of the passive, or the unstable comprehension of it, lies in the fact that it is interpreted as an active sentence. This hypothesis is supported by the structural relationship between passive and active sentences (Boeckx, 1998), that share the same structure until a certain point in the derivation (see structure in (1)).

It is possible that the population with Down syndrome has problems with the passive inasmuch as they interpret the first noun as agent/causer of the action/non-action, and the second noun as patient/theme. So what happens is: when they hear a passive sentence, they merge (put) the noun they hear first, which is the noun patient/theme, in 
the position that should be occupied by the noun agent/ causer, and merge the noun agent/causer in the position where the noun patient/theme should be. Since these are mergings that yield an active sentence, they will interpret the passive they hear as an active sentence. If an individual consistently interprets a passive sentence that way, he/she cannot produce or imitate it.

Such mergings are viable thanks to the structural identity between active and passive, as suggested by Boeckx (see structure in (1)). From the acquisition perspective, it makes a lot of sense to propose that the child confounds two structures if they are similar. So if both active and passive share the same initial structure, then it is easy to see why the child gets mixed up.

Before a passive sentence, around $50 \%$ of the time, the group fails to note that the agent/causer is not the first element of a passive sentence. Fa correctly interprets passive sentences.

Results like Fa's are not unheard of in the literature. A study conducted by Rondal (1995) showed that a French speaking woman with Down syndrome, Françoise, had almost normal linguistic complexity. The passive in particular had been acquired. The experiment Rondal conducted with Françoise employed sixty-four grammatical sentences, half actives and half long passives (borrowed from Rondal et al. 1990). All the words in the sentences occur frequently in French, the verbs were used in the present tense, and the nouns were preceded by definite articles and were in the singular form. Four kinds of sentences were constructed, and they varied in plausibility:

1) plausible and plausibly reversible sentences (Le papa est soigné par la maman "The father is nursed by the mother");

2) implausible but plausibly reversible sentences ( $L a$ maman est soigné par l'oiseau "The mother is nursed by the bird");

3) plausible but implausibly reversible sentences (L'oiseau est soigné par la maman "The bird is nursed by the mother");

4) implausible and not plausibly reversible sentences (Le divan est soigné par l'armoire "The sofa is nursed by the cupboard").

The investigator orally produced each sentence at a normal pace and neutral intonation. After each sentence, Françoise was requested to answer either an active question (Qui (verbe)? "Who (verbs)?)" or a passive question (Qui (est verbé? "Who (is verbed)?" about the logical subject (noun agent/causer) or about the logical object (noun patient/theme). She correctly interpreted sixty-one sentences. Out of the three sentences to which she did not give a correct answer, only one was a non-action passive sentence.

\section{Conclusion}

Based on works such as Maratsos (1974), it is assumed that lack of comprehension, or an unstable comprehension of the passive, is due to its interpretation as an active sentence. The structure adopted to explain the passive (Boeckx, 1998) makes this hypothesis strong, as passive and active are very similar until a certain point in the derivation (see structure in (1)). To derive an active sentence, the nouns agent and patient do not 'exchange' their positions in the syntactic tree. But to derive the passive, the nouns agent and patient have to 'exchange' positions. The hypothesis was that the reversible passive is interpreted as active because the individual, hearing the passive, and interpreting the first noun as agent/causer of the action/non-action, merges it in the position of the noun agent and merges the noun agent/causer in the patient/theme position, thus deriving an active sentence.

The hypothesis was tested by production, imitation and four comprehension experiments: three experiments, that involved action and non-action verbs, and reversible passives, tapped into the comprehension of the active and the passive voices; one experiment sought to establish whether the noun patient/theme was interpreted or not as agent/causer of the action/non-action. The findings are summarised below:

1) The adolescents with Down syndrome as a group do not produce passives, do not imitate long passives, and short passives are a struggle to imitate. Their understanding of long and short passives is at chance level, what is attributed to the fact that they are starting to understand them. So around $50 \%$ of the time they comprehend the passive as active, because they interpret the first noun of the passive as agent/causer.

2) Fa produces, imitates and comprehends passive sentences.

\section{Correspondence}

rubinmaraci@hotmail.com

\section{References}

Baker, M., Johnson, K. \& Roberts, I. (1989). Passive arguments raised. Linguistic Inquiry, 20, 219-251.

Bever, T.G. The cognitive basis for linguistic structures (1970). In Hayes, J.R. (Ed.), Cognition and Development of Language. New York: Wiley.

Boeckx, C. (1998). A Minimalist View on the Passive. University of Connecticut Occasional Papers in Linguistics, 2.

Chomsky, N. (1957). Syntactic Structures. Mouton Publishers, The Hague. 
De Villiers, J.G. \& De Villiers, P.A. (1978). Language Acquisition. Cambridge, MA.: Harvard University Press.

Fowler, A., Gelman, R. \& Gleitman, L. (1994). The Course of Language Learning in Children with Down Syndrome (1994). In Tager-Flusberg, H. (Ed.), Constraints on Language Acquisition: Studies of Atypical Children, (pp. 91-140). LEA.

Harwood, F.W. (1959). Quantitative study of the speech of Australian children. Language and Speech, 2, 23741.

Horgan, D. (1978). The development of the full passive. Journal of Child Language, 5, 65-80.

Hsu, J.R. \& Hsu, L.M. (1998). Issues in designing research and evaluating data pertaining to children's syntactic knowledge. In McDaniel, D., McKee, C. \& Cairns, H.S. (Eds.), Methods for Assessing Children's Syntax (pp. 303-377). Cambridge, MA. London, England: The MIT Press.

Jaeggli, O.A. (1986) Passive. Linguistic Inquiry, 17(4), 587-622.

Lust, B., Flynn, S. \& Foley, C. (1998). What children know about what they say: Elicited imitation as a research method for assessing children's syntax. In McDaniel, D., McKee, C. \& Cairns, H.S. (Eds.), Methods for Assessing Children's Syntax (pp. 55-76). Cambridge, MA. London, England: The MIT Press.

Maratsos, M.P. (1974). Children who get worse at understanding the passive: a replication of Bever. Journal of Psycholinguistic Research, 3, 65-74.

Maratsos, M.P., Fox, D.E.C., Becker, J.A. \& Chalkley, M.A. (1985). Semantic restrictions on children's passives. Cognition, 19, 167-191.

Marcel, M.M., Ridgeway, M.M., Sewell, D.H. \& Whelan, M.L. (1995). Sentence imitation by adolescents and young adults with Down's syndrome and other intellectual disabilities. Journal of Intellectual Disability Research, 39, 215-232.

Rondal, J. A. (1995). Exceptional Language Development in Down Syndrome. Cambridge: Cambridge University Press.

Rondal, J.A., Thibaut, J.P. \& Cession, A. (1990). Transitivity effects on children's sentence comprehension. European Bulletin of Cognitive Psychology, 10, 385400.

Rondal, J. A., Cession, A. \& Vincent, E. (1988). Compréhension des phrases déclaratives selon la voix et l'actionalité du verbe chez un groupe d'adultes trisomiques 21. Unpublished manuscript. Laboratoire de Psycholinguistique, Université of Liège, Liège.

Ring, M. \& Clahsen, H. (2006). Distinct Patterns of Language Impairment in Down Syndrome, Williams
Syndrome, and SLI: The case of syntactic chains. To appear in Journal of Neurolinguistics, 19.

Rubin, M. (2004). A passiva na Síndrome de Down. $\mathrm{PhD}$ Dissertation. Universidade Federal do Paraná, Curitiba, Brazil.

Rubin, M. (in progress). The passive in three-year-olds. Manuscript.

Sudhalter, V. \& Braine, M.D. (1985). How does comprehension of passives develop? A comparison of actional and experiential verbs. Journal of Child Language, 12, 455-470.

Strohner, J. \& Nelson, K. E. (1974). The young child's development of sentence comprehension: influence of event probability, nonverbal context, syntactic form, and strategies. Child Development, 45, 564-576. 